\title{
Severe Hepatotoxicity of Mithramycin Therapy Caused by Altered Expression of Hepatocellular Bile Transporters ${ }^{\mathbf{s}}$
}

\author{
Tristan M. Sissung, Phoebe A. Huang, Ralph J. Hauke, Edel M. McCrea, Cody J. Peer, \\ Roberto H. Barbier, Jonathan D. Strope, Ariel M. Ley, Mary Zhang, Julie A. Hong, \\ David Venzon, Jonathan P. Jackson, Kenneth R. Brouwer, Patrick Grohar, Jon Glod, \\ Brigitte C. Widemann, Theo Heller, David S. Schrump, and William D. Figg \\ Clinical Pharmacology Program (T.M.S., C.J.P., W.D.F.), Molecular Pharmacology Section (P.A.H., R.J.H., E.M.M., R.H.B., \\ J.D.S., A.M.L., W.D.F.), Biostatistics and Data Management Section (M.Z., J.A.H., D.V.), Pediatric Oncology Branch (P.G., J.G., \\ B.C.W.), Thoracic Surgery Branch, Center for Cancer Research, National Cancer Institute (D.S.S.), and Translational Hepatology \\ Section (T.H.), Liver Diseases Branch, National Institute of Diabetes and Digestive and Kidney Diseases, Bethesda, Maryland; and \\ BiolVT, ADME-Tox Division, Durham, North Carolina (J.P.J., K.R.B.)
}

Received October 12, 2018; accepted May 15, 2019

\begin{abstract}
Mithramycin demonstrates preclinical anticancer activity, but its therapeutic dose is limited by the development of hepatotoxicity that remains poorly characterized. A pharmacogenomics characterization of mithramycin-induced transaminitis revealed that hepatotoxicity is associated with germline variants in genes involved in bile disposition: $A B C B 4$ (multidrug resistance 3) rs2302387 and $A B C B 11$ [bile salt export pump (BSEP)] rs4668115 reduce transporter expression $(P<0.05)$ and were associated with $\geq$ grade 3 transaminitis developing 24 hours after the third infusion of mithramycin $(25 \mathrm{mcg} / \mathrm{kg}, 6$ hours/infusion, every day $\times 7$, every 28 days; $P<0.0040$ ). A similar relationship was observed in a pediatric cohort. We therefore undertook to characterize the mechanism of mithramycin-induced acute transaminitis. As mithramycin affects cellular response to bile acid treatment by altering the expression of multiple bile transporters (e.g., ABCB4, $A B C B 11$, sodium/taurocholate cotransporting polypeptide, organic solute transporter $\alpha / \beta$ ) in several cell lines [Huh7, HepaRG, HepaRG BSEP $(-/-)$ ] and primary human hepatocytes, we hypothesized that mithramycin inhibited bile-mediated activation of the farnesoid X receptor (FXR). FXR was downregulated in all hepatocyte cell lines and primary human hepatocytes $(P<$ 0.0001 ), and mithramycin inhibited chenodeoxycholic acid- and GW4046-induced FXR-galactose-induced gene 4 luciferase
\end{abstract}

reporter activity $(P<0.001)$. Mithramycin promoted glycochenodeoxycholic acid-induced cytotoxicity in $A B C B 11(-/-)$ cells and increased the overall intracellular concentration of bile acids in primary human hepatocytes grown in sandwich culture $(P<$ 0.01). Mithramycin is a FXR expression and FXR transactivation inhibitor that inhibits bile flow and potentiates bile-induced cellular toxicity, particularly in cells with low ABCB11 function. These results suggest that mithramycin causes hepatotoxicity through derangement of bile acid disposition; results also suggest that pharmacogenomic markers may be useful to identify patients who may tolerate higher mithramycin doses.

\section{SIGNIFICANCE STATEMENT}

The present study characterizes a novel mechanism of druginduced hepatotoxicity in which mithramycin not only alters farnesoid X receptor ( $F X R$ ) and small heterodimer partner gene expression but also inhibits bile acid binding to FXR, resulting in deregulation of cellular bile homeostasis. Two novel singlenucleotide polymorphisms in bile flow transporters are associated with mithramycin-induced liver function test elevations, and the present results are the rationale for a genotype-directed clinical trial using mithramycin in patients with thoracic malignancies.
This work was supported by the Intramural Research Program of the National Institutes of Health [Grant ZIA BC 010627].

https://doi.org/10.1124/mol.118.114827.

S This article has supplemental material available at molpharm.aspetjournals.org.

\section{Introduction}

Mithramycin is a DNA-binding antineoplastic agent initially assessed as a cancer therapeutic in the 1960s (Kofman and Eisenstein, 1963; Sewell and Ellis, 1966; Ream et al., 1968). Previous work demonstrated that the antitumor effects of mithramycin are primarily mediated by direct and selective inhibition of specificity protein 1 binding to guanine- and

ABBREVIATIONS: ALT, alanine aminotransferase; AST, aspartate aminotransferase; BSEP, bile salt export pump; CDCA, chenodeoxycholic acid; CsA, cyclosporine A; d4, deuterium-labeled; DMET, drug metabolizing elimination and transport; FXR, farnesoid X receptor; Gal4, galactoseinduced gene 4; GAPDH, glyceraldehyde-3-phosphate dehydrogenase; GCA, glycocholic acid; GCDC, glycochenodeoxycholic acid; GCDCA, glycol-CDCA; LFT, liver function test; MPM, malignant pleural mesothelioma; NTCP, sodium/taurocholate cotransporting polypeptide; OST, organic solute transporter; PCR, polymerase chain reaction; QTS, Qualyst Transporter Solutions; RXR, retinoic acid receptor; SCHH, sandwich-cultured human hepatocytes; SHP, small heterodimer partner; SNP, single-nucleotide polymorphism; TCA, taurocholic acid; TCDCA, tauro-CDCA. 
cytosine-rich promoter elements (Blume et al., 1991; Lombó et al., 2006), resulting in a variety of anticancer effects: decreased cell growth, increased apoptosis, decreased angiogenesis, and tissue differentiation ( $\mathrm{Li}$ and Davie, 2010; Safe et al., 2014). Mithramycin simultaneously activates p53 signaling in thoracic tumors, resulting in growth arrest, senescence, and apoptosis (Zhang et al., 2012). Additional preclinical work has implicated mithramycin as an inhibitor of the EWS-FLI1 oncogene that drives approximately $85 \%$ of Ewing's sarcomas (Grohar et al., 2011).

Given the dramatic dose-dependent inhibitory effects of mithramycin on stem cell signaling (Zhang et al., 2012; Singh et al., 2017) with concomitant decreases in proliferation and tumorigenicity of lung and esophageal cancer, as well as malignant pleural mesothelioma (MPM) cells in vitro and in vivo (Zhang et al., 2012; Rao et al., 2016), recent efforts have focused on evaluation of mithramycin in patients with thoracic malignancies. Despite its promising preclinical activity in numerous advanced malignancies (Grohar et al., 2011; Sankpal et al., 2012; Zhang et al., 2012; Rao et al., 2016; Li et al., 2017; Liu et al., 2017; Singh et al., 2017), administration of mithramycin in cancer patients has been accompanied by systemic toxicities (Curreri and Ansfield, 1960; Baum, 1968; Kennedy, 1970), including hepatocellular damage (Green and Donehower, 1984), severe transaminitis (Reuben et al., 2010; Grohar et al., 2017), and acute hepatic injury within days of initiating therapy (https://livertox.nih.gov/Plicamycin.htm). Prolonged cell culture concentrations between 20 and $100 \mathrm{nM}$ (every 24 hours) are sufficient to induce growth arrest and apoptosis in cancer cells, and a 50-100 nM plasma concentration is required to induce tumor regression in animals; however, these concentrations have not been clinically achieved in humans (Sankpal et al., 2012; Rao et al., 2016; Grohar et al., 2017; Li et al., 2017; Liu et al., 2017; Singh et al., 2017).

The mechanism of mithramycin-induced hepatotoxicity currently remains poorly characterized and has limited its clinical use. In an ongoing clinical trial at the National Cancer Institute, significant dose-limiting hepatotoxicity that was observed in approximately $75 \%$ of patients treated with mithramycin prompted initiation of a pharmacogenetics-based investigation of potential corresponding single-nucleotide polymorphisms (SNPs). To elucidate mithramycin-induced hepatic injury and optimize mithramycin therapy, we discovered and characterized a novel mechanism by which mithramycin blocks hepatic transport of bile acids, resulting in cholestasis and subsequent hepatotoxicity. Our findings support the continued clinical evaluation of mithramycin using genotype-directed precision medicine techniques to identify patients with genetic profiles most conducive to mithramycin therapy.

\section{Materials and Methods}

Patients, Treatments, and Clinical Samples. Twelve patients (10 males; two females; median age 51 years; range $40-72$ years) with refractory thoracic malignancies received 6 hours mithramycin infusions every day $\times 7$, every 28 days. Response rates following two cycles, pharmacokinetics, and systemic toxicities (cycle 1) were evaluated. Genotype analysis of mithramycin-treated patients was conducted using the drug metabolizing elimination and transport (DMET) array (Affymetrix, Santa Clara, CA). Human hepatocytes for gene expression analysis were collected from cadavers (Bioreclaimation, Baltimore,
MD). Additional samples were obtained from a previously published study testing mithramycin outcomes in pediatric patients (Grohar et al., 2017). Written informed consent was obtained from all patients before enrollment on the trials (NCT01624090 and NCT01610570), and all studies were approved by the Institutional Review Board of the National Cancer Institute.

Pharmacokinetics. Blood samples were collected at predose, mid infusion ( 3 hours post start), end of infusion ( 6 hours post start), and $0.25,0,5,7,2,3,5,7,9,11$, and 18 hours post end of infusion on cycle 1 , day 1 . An end of infusion sample was collected on cycle 1 , day 2 , as was a predose and end of infusion on cycle 1 , day 5 . For severe combined immunodeficiency mice (strain code 561; Charles River, Wilmington, MA) plasma was frozen after 5, 10, and 15 minutes, respectively, following a $1.27 \mu \mathrm{g} / \mathrm{kg}$ dose in normal saline. The plasma or animal liver homogenates were frozen until analysis by a validated assay, as previously published (Roth et al., 2014). Individual pharmacokinetic parameters were calculated using noncompartmental methods utilizing Phoenix WinNonlin v6.3 (Certara, Cary, NC). The National Cancer Institute is accredited by the Association for Assessment and Accreditation of Laboratory Animal Care International and follows the Public Health Service Policy for the Care and Use of Laboratory Animals. Animal care was provided in accordance with the Guide for the Care and Use of Laboratory Animals. The study protocol was approved by the National Cancer Institute Animal Care and Use Committee.

Reagents. Chenodeoxycholic acid (CDCA), taurocholic acid (TCA), glycochenodeoxycholic acid (GCDC), deoxycholic acid, litholic acid, cyclosporine A (CsA), as well as mithramycin were purchased from Sigma-Aldrich (St. Louis, MO). Deuterium-labeled (d4)-CDCA was purchased from Toronto Research Chemicals (Toronto, Canada).

Transporter-certified human primary hepatocytes were obtained from ThermoFisher Scientific (Hu8246; Waltham, MA). Primary human hepatocytes were cultured with proprietary cell culture media formulations developed by Qualyst Transporter Solutions (QTS), now a part of ADME-Tox Division of BioIVT. QualGro Seeding Medium and QualGro Culture Induction Medium supplemented with Matrigel (Corning, Tewksbury, MA) were from QTS (Durham, NC). The base medium (Dulbecco's modified Eagle's medium) used by QTS and additional supplements, including FBS, used for cell culture were from Gibco (Carlsbad, CA) and Corning.

Cell Line and Maintenance. Human hepatocellular carcinoma cells (Huh7) were purchased from National Institutes of Biomedical Innovation, Health, and Nutrition JCRB Cell Bank (Osaka, Japan). Huh7 cells were cultured in Dulbecco's modified Eagle's medium containing $10 \% \mathrm{FBS}, 50 \mathrm{U} / \mathrm{ml}$ penicillin, and $50 \mathrm{mg} / \mathrm{ml}$ streptomycin. HepaRG 5F control cells (MTOX1010) and bile salt export pump (BSEP) knockout HepaRG cells (MTOX1018) were obtained from Sigma-Aldrich and cultured in William's E media containing HepaRG thaw, plate, and general purpose medium and GlutaMAX supplements (Thermo Scientific), $50 \mathrm{U} / \mathrm{ml}$ penicillin, and $50 \mathrm{mg} / \mathrm{ml}$ streptomycin. Cells were incubated at $37^{\circ} \mathrm{C}$ in an atmosphere containing $5 \%$ $\mathrm{CO}_{2}$ and $95 \%$ humidity.

Sandwich-Cultured Primary Human Hepatocyte Cultures. Sandwich-cultured human hepatocytes $(\mathrm{SCHH})$ were established by thawing transporter-certified cryopreserved hepatocytes, according to the manufacturer's instructions. Once thawed, the cells were suspended in QualGro seeding medium, a QTS proprietary product, at a density of 0.8 million viable cells $/ \mathrm{ml}$ and seeded onto BioCoat 24 -well ( $\sim 0.4$ million cells/well) cell culture plates purchased from Corning. Following the initial seeding, cells were allowed to attach for 2-4 hours, and then were rinsed and fed with $500 \mu \mathrm{l} /$ well warm $\left(37^{\circ} \mathrm{C}\right)$ QualGro seeding medium. After a culture time of 18-24 hours, the seeding medium was removed. Subsequently, the cells were fed and overlaid with QualGro induction medium supplemented with $0.25 \mathrm{mg} / \mathrm{ml}$ Matrigel (Corning).

Gene Expression Assays. Cells were cultured, as described above, and treated with vehicle control (0.1\% DMSO), TCA $(100 \mu \mathrm{M})$, CDCA $(100 \mu \mathrm{M})$, mithramycin $(25 \mathrm{nM})$, or a combination 
for 72 hours. Total RNA extraction was performed using the QIAshredder and RNAeasy mini kit (Qiagen, Valencia, CA) per the manufacturer's protocol. RNA concentration was determined using a NanoDrop spectrophotometer (Molecular Devices, Sunnyvale, CA). RNA from cells was reverse transcribed per $30 \mu \mathrm{l}$ cDNA synthesis reaction using the Superscript III First-Strand Synthesis System for reverse-transcription polymerase chain reaction (PCR; Invitrogen) per the manufacturer's protocol. Detection of $A B C B 11, A B C B 4, F X R$, $N T C P, O S T \alpha$, and $O S T \beta$ transcript expression was conducted using TaqMan gene expression assays [Life Technologies (Thermo), Grand Island, NY] per the manufacturer's instructions on a StepOnePlus Real-Time PCR system (Applied Biosystems, Foster City, CA).

Human ABC and Drug Transporter Arrays. Huh7, HepaRG, and BSEP knockout HepaRG cells were cultured, as described above, and treated with vehicle control $(0.1 \%$ DMSO) or a noncytotoxic (or minimally cytotoxic) concentration of mithramycin $(25 \mathrm{nM})$ for 72 hours. Detection of different transporter transcripts was conducted using TaqMan human ABC transporter and human drug transporter arrays [Life Technologies (Thermo)] per the manufacturer's instructions on a StepOnePlus Real-Time PCR system (Applied Biosystems).

Western Blot Analysis. Cells were cultured, as described above, and plated in 10-cm tissue culture dishes. Cells were treated with vehicle control ( $0.1 \%$ DMSO) or a noncytotoxic (or minimally cytotoxic) concentration of mithramycin $(25 \mathrm{nM})$ for 72 hours. Cells were then lysed with ice-cold radioimmunoprecipitation assay lysis buffer (SigmaAldrich) complete with protease inhibitors (Nacalai Tesque, Kyoto, Japan). After 30 minutes of incubation on ice, cell lysates were centrifuged at $7500 \mathrm{rpm}$ for 10 minutes. Supernatants were collected, and total protein concentrations were determined using a bicinchoninic acid assay (Thermo Scientific), according to the manufacturer's protocol.

Cell lysates were subjected to SDS-PAGE and analyzed by Western blotting with anti-ABCB11 polyclonal antibody (ab112494; Abcam), anti-ABCB4 polyclonal antibody (PA5-13106; Invitrogen), anti-actin (C-2) monoclonal antibody (sc-8432; Santa Cruz Biotechnology), antifarnesoid X receptor (FXR)-A polyclonal antibody (AB10304; Millipore), anti-SLC10A1 polyclonal antibody (HPA042727; Sigma-Aldrich), antiorganic solute transporter (OST) $\alpha$ (C-term) polyclonal antibody (SAB1306154; Sigma-Aldrich), anti-SLC51B polyclonal antibody (HPA008533; Sigma-Aldrich), and anti-glyceraldehyde-3-phosphate dehydrogenase (GAPDH) monoclonal antibody (G8795; Sigma-Aldrich).

Primary antibodies were immunoreacted with fluorophoreconjugated goat anti-mouse and anti-rabbit IgG. Bound antibodies were visualized, and densitometry was completed via the Odyssey Infrared Imaging System and Odyssey software (LI-COR). Antibody dilutions were as follows: rabbit $\mathrm{pAB}$ to $\mathrm{ABCB} 11,1: 1500$; rabbit $\mathrm{pAB}$ to ABCB4, SLC10A1, and SLC51B, 1:100; rabbit pAB to FXR, 1:500; rabbit $\mathrm{pAB}$ to $\mathrm{OST} \alpha$ and mouse $\mathrm{mAB}$ to actin, 1:1000; mouse $\mathrm{mAB}$ to GAPDH, 1:2000; M800 = IRDye 800CW goat anti-mouse (incubated with actin) $1: 20,000, \mathrm{R} 800=$ IRDye $800 \mathrm{CW}$ goat anti-rabbit (incubated with ABCB11 and ABCB4) 1:15,000, R800 = IRDye 800CW goat anti-rabbit (incubated with FXR, SLC10A1, OST $\alpha$, and SLC51B) $1: 10,000$, and M680 = IRDye 680RD goat anti-mouse (incubated with GAPDH) $1: 20,000$.

TCA Uptake Assay. Huh7 cells were cultured, as described above, and plated in 96 -well plates. TCA uptake assay was performed utilizing Gentest BSEP Vehicle Assay Kit (Corning) per the manufacturer's instructions.

Luciferase Reporter Assays. Cells were cultured, as described above, and plated into 96-well plates with Opti-MEM reduced serum media (Invitrogen) and transiently transfected with Nuclear Receptor Cignal Reporter Array reporter plasmids (Qiagen) using Attractene transfection reagent (Qiagen) per the manufacturer's instructions. Twenty-four hours after transfection, cells were treated with mithramycin $(25 \mathrm{nM})$ in Opti-MEM media with $0.5 \% \mathrm{FBS}$. Twenty-four hours after treatment, cell Firefly luciferase activity was determined and normalized to Renilla luciferase activity using the Dual-Luciferase Reporter Assay System (Promega, Madison, WI). Measurements were taken on a GloMax-Multi Detection System microplate reader (Promega).
Human FXR (NR1H4) and retinoic acid receptor (RXR) $\alpha$ (NR1B1) Nuclear Receptor Reporter Assay Systems as well as Live Cell Multiplex Assays were purchased from Indigo Biosciences (State College, PA). Functional activities of DY268 (reference antagonist; concentration range $0-33,333 \mathrm{nM}$ ) and mithramycin (concentration range 0-300 $\mathrm{nM})$ in the presence of reference agonist GW4064 (300 nM), retinoic acid $(120 \mathrm{nM})$, or the FXR-ligand CDCA $(50 \mu \mathrm{M})$ were assessed, according to the manufacturer's instructions. Fluorescence and luminescence measurements were taken using the SpectraMax M2 Microplate Reader and the GloMax-Multi Detection System, respectively.

Bile Acid Cytotoxicity Analysis. HepaRG wild-type and BSEP knockout cells were cultured, as described above, and treated with vehicle control (0.1\% DMSO) or mithramycin ( $25 \mathrm{nM})$ for 72 hours. Cells were then treated with media containing $100 \mu \mathrm{M}$ GCDC, deoxycholic acid, or litholic acid for 24 hours. Cell viability was assayed using the Dojindo Cell Counting Kit-8 (Dojindo Molecular Technologies, Rockville, MD), according to the manufacturer's instructions.

Hepatobiliary Disposition of Endogenous Bile Acids in SCHH. SCHH were established, as described above, and the hepatobiliary disposition of endogenous bile acids was assessed following 72 hours of treatment with d4-CDCA $(100 \mu \mathrm{M})$, CsA $(10 \mu \mathrm{M})$, or mithramycin $(20 \mu \mathrm{M})$. SCHH were treated daily beginning on day 2 of culture for 3 days with fresh dosing solutions composed of test article and QualGro induction medium. All compound stock solutions were prepared in $100 \%$ DMSO and diluted $1000 \times$ directly into QualGro induction medium. Twenty-four hours after last dosing, assessments of gene expression and endogenous bile acid disposition were determined.

Following the designated exposure period, SCHH were washed once with one volume of Hanks' balanced salt solution and lysed by addition of $0.3 \mathrm{ml}$ Qiagen RNeasy lysis buffer supplemented with $\beta$-mercaptoethanol and frozen at $-80^{\circ} \mathrm{C}$ until processed for total mRNA isolation and subsequent quantitative reverse-transcription PCR analysis, as described above.

After 72 hours of exposure, $\mathrm{SCHH}$ were prepared for endogenous bile acid disposition analysis. Cell culture medium was removed from $\mathrm{SCHH}$ and stored at $-80^{\circ} \mathrm{C}$ for endogenous bile acid composition analysis. After removal of cell culture media, the tight junctions of untreated and treated SCHH were modulated using B-CLEAR technology (QTS), as previously described (Jackson et al., 2016; Zhang et al., 2017). Sample preparation and bioanalysis of endogenous bile acids including tauro-CDCA (TCDCA), glycol-CDCA (GCDCA), glycocholic acid (GCA), and TCA using liquid chromatography with tandem mass spectrometric detection were performed, as previously described (Jackson et al., 2016; Zhang et al., 2017).

Statistical Considerations. Associations of liver function test (LFT) grades and elevations with pharmacokinetic parameters and genotypes were tested using Cochran-Armitage, Mann-Whitney, and Jonckheere-Terpstra tests, as appropriate. Transporter expression levels were log-transformed, standardized to controls, analyzed as t-distributed variates for estimates of means and confidence intervals, and then exponentiated back as fold changes. Transporter expression treated with CDCA or GCDC alone or in combination with mithramycin was tested in one-way ANOVA of log-transformed levels or in MannWhitney tests, depending on consistency with distributional assumptions. Bile acid accumulation and nuclear receptor reporter assay data were also assessed by one-way ANOVA, with the latter corrected by the Hochberg method for the number of receptors tested. Data analysis was conducted with SAS/STAT(R) software (version 9.3), and plots were generated using GraphPad Prism (version 7). All data are presented as the mean and S.E.M., unless otherwise indicated. $P$ values are two-tailed and are not corrected for multiple comparisons, except as noted above.

\section{Results}

Genetic Variants Associated with MithramycinInduced Hepatotoxicity. Patients with various malignancies (six MPM, two esophageal cancers, two lung cancers, two 
synovial sarcomas with pulmonary metastases; $n=12$ ) were treated with mithramycin. Twenty cycles were administered in 12 patients, all of whom were evaluable for toxicities. No objective responses were observed in seven evaluable patients. Nine patients experienced transient, asymptomatic doselimiting transaminitis at $25 \mathrm{mcg} / \mathrm{kg}$ per infusion. Percutaneous biopsies revealed apoptotic hepatocellular death. Three patients (two with MPM; one esophageal cancer) had no hepatotoxicity and tolerated dose escalation to $30 \mathrm{mcg} / \mathrm{kg}$ per infusion. Peak and steady state mithramycin levels were 20 and $8 \mathrm{nM}$, respectively.

However, the development of dose-limiting transaminitis in nine of these individuals prevented the achievement of plasma concentrations sufficient for tumor regression in preclinical animal models (50-100 nM) (Rao et al., 2016), instead resulting in a $C_{\max }$ of approximately $20 \mathrm{nM}$. Clinical LFTs revealed that mithramycin caused a $>13$-fold increase in geometric mean (95\% confidence interval) of both alanine aminotransferase (ALT) [21 U/l (12-36) vs. 363 U/l (138-895)] and aspartate aminotransferase (AST) [20 U/l (13-29) vs. $269 \mathrm{U} / \mathrm{l}$ (116v622)], indicative of hepatocellular damage and/or injury. Of the 12 patients treated in this study, eight patients experienced clinically significant ( $\geq$ grade 3 ) transaminase elevations approximately 24 hours following the third infusion of mithramycin (Fig. 1A). AST and ALT levels were strongly correlated; 10 patients had equal grades of ALT and AST elevation, whereas two patients with grade 1 AST had grades 0 and 2 ALT toxicity. Mithramycin pharmacokinetic parameters were not associated with transaminase elevations following mithramycin therapy ( $P \geq 0.20$; Fig. 1, B-D).

We therefore sought to identify interindividual genetic variations potentially underlying the observed transaminase elevations. Using the Affymetrix DMET Plus array (Arbitrio et al., 2016), genotyping analysis revealed polymorphisms in two genes ( $A B C B 4$ rs2302387 and $A B C B 11$ rs4668115; encoding the transporters multidrug resistance 3 and BSEP, respectively) most strongly associated with AST and ALT elevations ( $P \leq 0.027$; Supplemental Fig. 1). Individuals carrying wild-type alleles at both loci $(n=4)$ had grade $0-2$ AST and ALT increases, whereas all other patients with any variant in either gene $(n=8)$ had $\geq$ grade 3 transaminase elevations (both $P=0.0040$; Fig. 1E). These polymorphisms are in strong linkage with numerous SNPs in these genes (Supplemental Fig. 2). Other polymorphisms were either significantly associated with AST and ALT rises [rs6774801 (CYP8B1) and rs506008 (GSTM4) $(P \leq 0.042)$ ], or trending with them [rs717620 (ABCC2, encoding MRP2) $(P \leq 0.065)$; Supplemental Fig. 1]. Using a cellular uptake assay, we further determined mithramycin is not an inhibitor of ABCB11 (BSEP) transport (Supplemental Fig. 3).

We acquired human hepatocytes collected from cadavers to confirm that patients who were wild-type at $A B C B 11$ rs4668115 had greater expression of $A B C B 11$, whereas those who were wild-type at both sites had greater expression of both $A B C B 4$ and $A B C B 11$ (Fig. $1 F$ ). We additionally validated our findings using clinical samples from a study evaluating mithramycin outcomes in pediatric patients (Grohar et al., 2017), and again observed a statistically significant association between the $A B C B 11$ SNP and mithramycin-induced LFT elevations ( $P=0.11$ for both ALT and AST elevations) (Fig. 1G). Due to unsuccessful PCR, we were unable to ascertain genotype at $A B C B 4$ in these samples. Because variation in the genes identified by DMET analysis to be strongly associated with mithramycin-mediated AST and ALT elevations could alter bile synthesis and transport (Bohan and Boyer, 2002; Arbitrio et al., 2016), we hypothesized that mithramycin induces cholestasis by altering the expression of hepatic transporters regulating bile flow, primarily ABCB4 and ABCB11.

Mithramycin Alters Expression of Hepatic Bile Acid Transporters. Bile acid transport in the liver is mediated by numerous transporters functioning on both the canalicular and basolateral membranes of hepatocytes. These hepatic transporters are involved in bile acid emulsification and in regulating the intracellular and biliary concentrations of bile acids (Fig. 2A) (Bohan and Boyer, 2002; Dawson et al., 2009). Given that both genetic defects and alterations in hepatobiliary bile transporters have been implicated in the pathogenesis and pathophysiology of cholestatic liver injury (Halilbasic et al., 2013), we evaluated the effects of mithramycin treatment (at the $C_{\max }$ concentration of approximately $25 \mathrm{nM}$, as observed in Fig. 1B) on transporter expression in human liver cell lines. We first confirmed that mithramycin $(1.27 \mu \mathrm{g} / \mathrm{kg})$ plasma concentration in mice matched hepatic concentrations 10 minutes after dosing [mean $(95 \%$ confidence interval $)=$ $0.54(0.40-0.69)$ and $0.44 \mathrm{nM}(0.00-1.04)$, for plasma and liver, respectively, $n=6$ per treatment]. In Huh7 cells, mithramycin (25 nM, 72 hours) was minimally cytotoxic (Fig. 2B) and lowered the expression of SLC51A (encoding OST $\alpha$ ), ABCB11, and $S L C O 1 B 3$ while simultaneously increasing the expression of $S L C 51 B$ (encoding OST $\beta$ ), ABCC3 (encoding MRP3), $A B C B 4$, and $A B C B 1$ (encoding P-glycoprotein; $P \leq 0.023$; Fig. $2 \mathrm{C})$. Mithramycin also altered the expression of many other uptake and efflux transporters (Supplemental Fig. 4).

As $A B C B 4$ and $A B C B 11$ are both regulated by similar factors that are affected by bile acid treatment (Plass et al., 2002; Huang et al., 2003), we next assessed whether mithramycin treatment affected the bile-mediated induction of these transporters. CDCA caused a 1.55-fold upregulation of $A B C B 4$ that was not abrogated by mithramycin. CDCA also upregulated $A B C B 11$ (57-fold), and mithramycin strongly interfered with bile-mediated $A B C B 11$ inducibility $(P=0.0022$; Fig. 2D). In HepaRG and HepaRG BSEP (-/-) cells, mithramycin lowered the expression of most transporters while raising the expression of some (Fig. 2E). Upon administration of bile acids, GCDC lowered the expression of both $A B C B 4$ and $A B C B 11$ in HepaRG cells by $34 \%$ and $28 \%$, respectively, whereas CDCA lowered the expression of $A B C B 4$ by $20 \%$ and raised the expression of $A B C B 11$ (2.5-fold) (Fig. $2 \mathrm{~F}$ ). Other transporters involved in bile acid uptake and efflux [sodium/taurocholate cotransporting polypeptide (NTCP), OST $\alpha$, and OST $\beta$ ] (Bohan and Boyer, 2002; Dawson et al., 2009) were also differentially regulated by administration of mithramycin and bile acids (Fig. 2G). We therefore reasoned that mithramycin interferes with the expression of several transporters contributing to normal bile acid homeostasis in the liver.

Mithramycin-Mediated Downregulation of FXR Is Associated with Increased Bile Acid Toxicity. Bile acid synthesis, metabolism, and circulation are under tight regulation by FXR, for which bile acids are physiologic ligands (Makishima et al., 1999). FXR mediates hepatic bile acid efflux by inducing the expression of ABCB4 and ABCB11 to transport phosphatidylcholine and bile, respectively, to the canalicular lumen (Plass et al., 2002; Huang et al., 2003). FXR 
A

\begin{tabular}{|l|l|l|l|l|l|}
\hline Parameter & $\begin{array}{l}\text { Grade 0 } \\
(\mathbf{n}=)\end{array}$ & $\begin{array}{l}\text { Grade 1 } \\
(\mathbf{n}=)\end{array}$ & $\begin{array}{l}\text { Grade 2 } \\
(\mathbf{n}=)\end{array}$ & $\begin{array}{l}\text { Grade 3 } \\
(\mathbf{n}=)\end{array}$ & $\begin{array}{l}\text { Grade 4 } \\
(\mathbf{n}=)\end{array}$ \\
\hline $\begin{array}{l}\text { ALT } \\
(\mathrm{n}=12)\end{array}$ & 2 & 0 & 2 & 6 & 2 \\
\hline $\begin{array}{l}\text { AST } \\
(\mathrm{n}=12)\end{array}$ & 1 & 2 & 1 & 6 & 2 \\
\hline
\end{tabular}

B
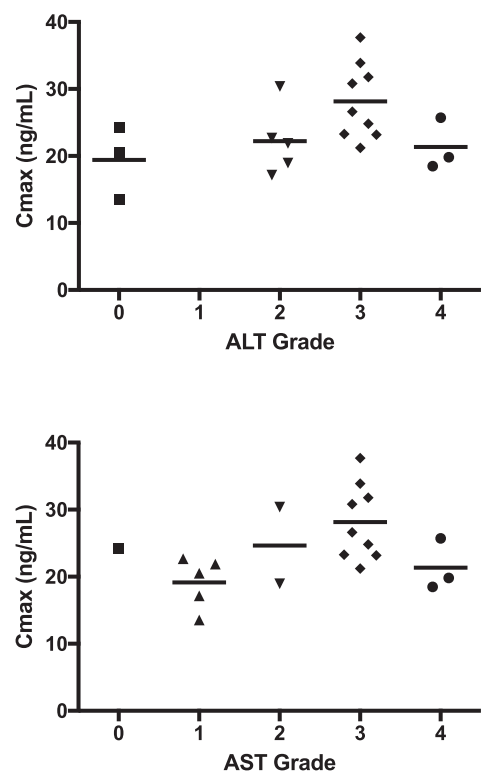

E
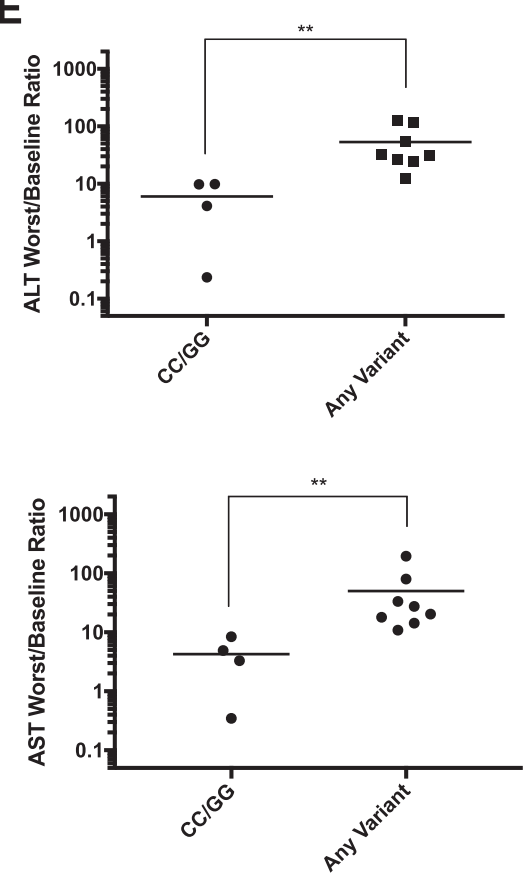

C
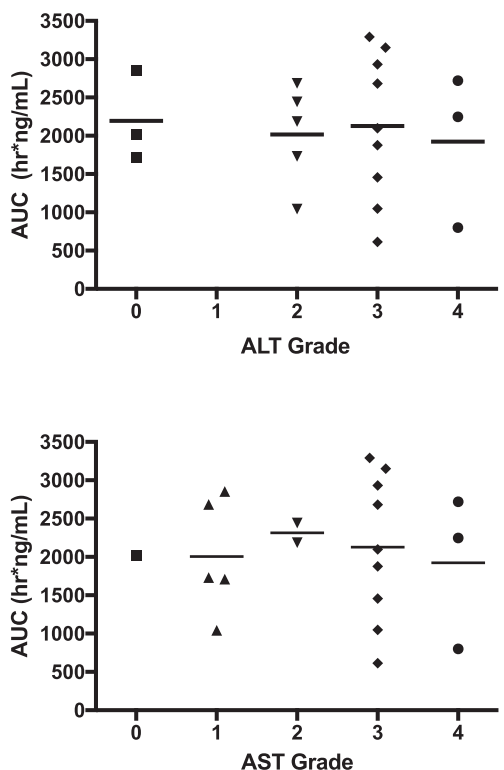

F
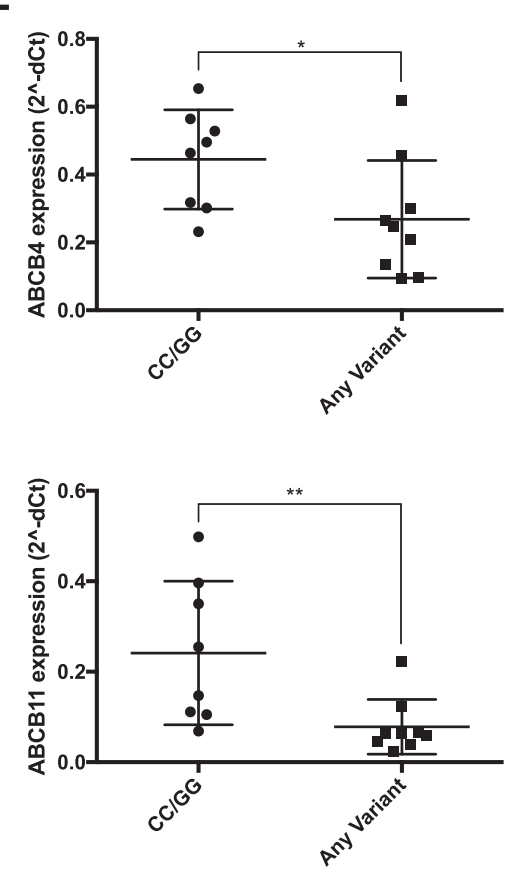

D
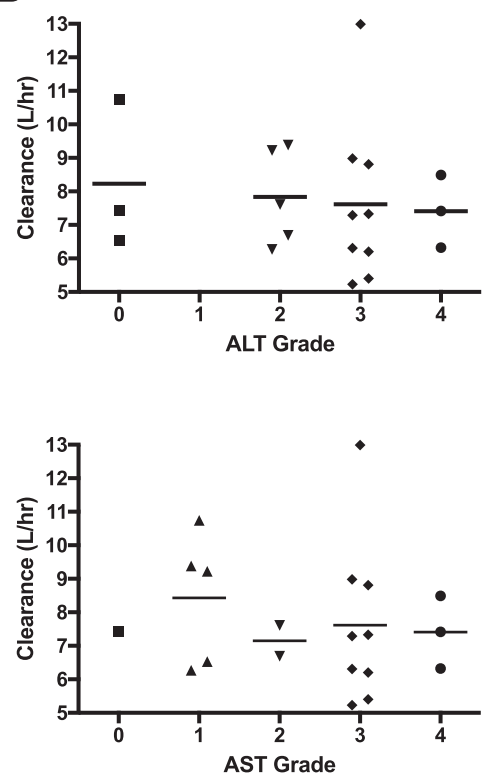

G
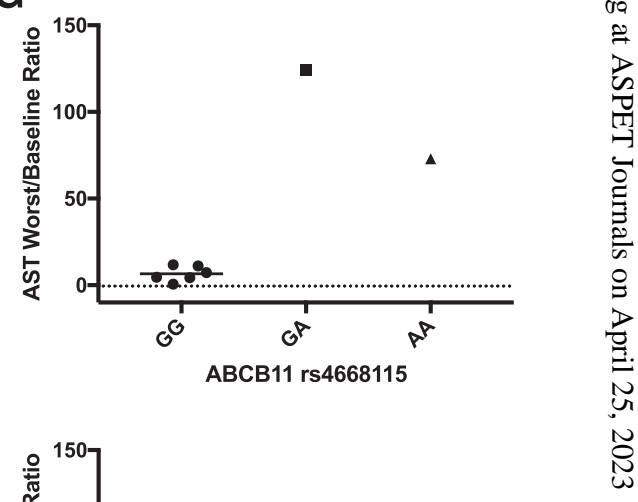

Fig. 1. Twelve adult patients with thoracic malignancies were administered mithramycin in a Phase II clinical trial. (A) LFT values were conducted in 20 cycles and analyzed for highest grade toxicity. Pharmacokinetic analysis was conducted, and ALT and AST toxicity grade were plotted vs. (B) $C_{\text {max }},(\mathrm{C})$ area under the curve, and (D) clearance. Means are shown by bars. (E) The highest ALT or AST test value for each patient was associated with a combination of two SNPs in $A B C B 4$ (rs2302387) and $A B C B 11$ (rs4668115). (F) Total hepatocyte $A B C B 4$ and $A B C B 11$ gene expression was measured using quantitative PCR and plotted according to combined rs2302387/rs4668115 genotype. (G) Genotype of $A B C B 11$ (rs4668115) was confirmed to be associated with LFT elevations in pediatric patients treated with mithramycin. ${ }^{*} P<0.05$ and $* * P<0.01$. 


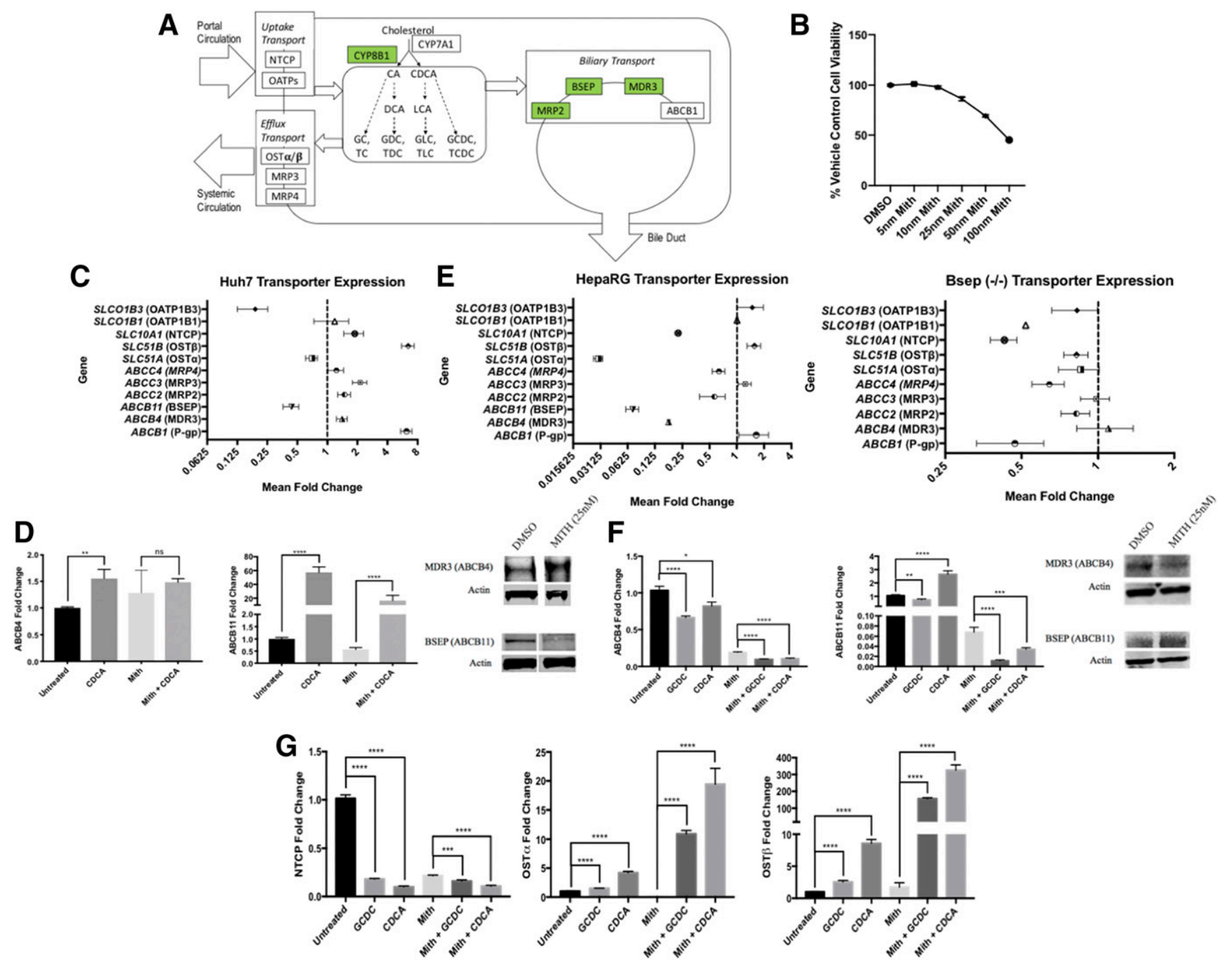

Fig. 2. (A) Bile acid transport in the liver is mediated by various transporters functioning on both the canalicular and basolateral membranes of hepatocytes that efflux bile acids or phosphatidylcholine. Genes with polymorphic variants associated with clinical transaminitis are highlighted in green. In Huh7 cells, (B) $25 \mathrm{nM}$ mithramycin was minimally cytotoxic and (C) affected the expression of several transporters. (D) CDCA upregulated $A B C B 4$ in Huh7 cells regardless of the presence of mithramycin, whereas both TCA and CDCA upregulated $A B C B 11$, which was inhibited by mithramycin. In HepaRG and HepaRG BSEP $(-/-)$ cells, (E) mithramycin downregulated 6/11 and 8/11 bile transporters, respectively. (F) CDCA caused downregulation of $A B C B 4$ and upregulation of $A B C B 11$ in HepaRG cells. Mithramycin further reduced the expression of ABCB4 and ABCB11, while interrupting the inducibility of $A B C B 11$. (G) Expression of other transporters was also altered by administration of mithramycin and CDCA. *P $<0.05$; ** $P<0.01 ; * * P<0.001 ;$ and $* * * * P<0.0001$. ns, non-significant.

inhibition would also be expected to directly increase the expression of OST $\beta$ and indirectly increase NTCP expression by blocking FXR-regulated SHP transcription. Although NTCP expression decreased, the effects of direct FXR inhibition were observed in the HepaRG cell line. We therefore assessed the effects of mithramycin on FXR and SHP expression and function. Mithramycin lowers FXR relative mRNA and protein expression in Huh7, HepaRG, Bsep (-/-) knockout cells, and in primary human hepatocytes $(67 \%, 57 \%, 55 \%$, $34 \%$, respectively; $P<0.0001$; Fig. $3, \mathrm{~A}$ and $\mathrm{B}$ ).

Mithramycin also inhibited the ligand-dependent (CDCA and GW4064) signaling of a fusion receptor of the FXR ligand binding domain and a galactose-induced gene 4 (Gal4) DNA binding domain from yeast (Fig. 3C) (Merk et al., 2014) and exhibited stronger inhibition of CDCA-FXR signaling than DY268 by $25 \%(P=0.0006)$. Mithramycin did not inhibit a RXR ligand binding domain linked to the same Gal4 DNA binding domain (Supplemental Fig. 5), despite its ability to bind guanine- and cytosine-rich DNA promoter elements. In Huh7, HepaRG, and HepaRG BSEP (-/-) cells, mithramycin did not consistently inhibit other nuclear receptors in reporter assays (androgen receptor, glucocorticoid receptor, hepatocyte nuclear factor 4, liver x receptor alpha, peroxisome proliferator-activated receptor alpha, progesterone receptor, retinoic acid receptor, retinoid $\mathrm{x}$ receptor, vitamin $\mathrm{D}$ receptor), although it unexpectedly decreased basal estrogen receptor activity $(P=0.015$ for Huh7, $P=0.0026$ for HepaRG, and $P=0.0029$ for BSEP knockout cells; Supplemental Fig. 6). In spite of FXR inhibition, SHP expression increased after mithramycin treatment (Fig. 3D), which is consistent with the unexpected decrease in HepaRG NTCP expression despite FXR inhibition (Fig. 2G).

We next hypothesized that, by deregulating bile acidmediated FXR regulation, mithramycin treatment would increase the cytotoxicity of GCDC treatment in BSEP (-/-) cells lacking BSEP expression. Mithramycin did not increase 
A

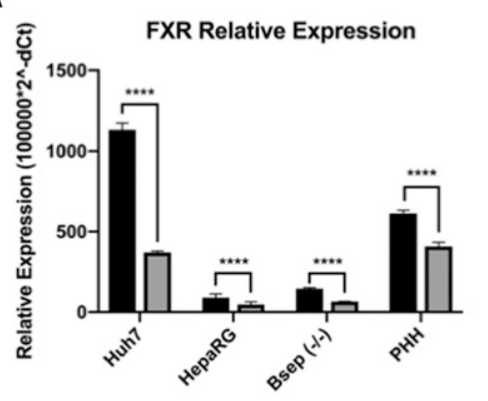

D

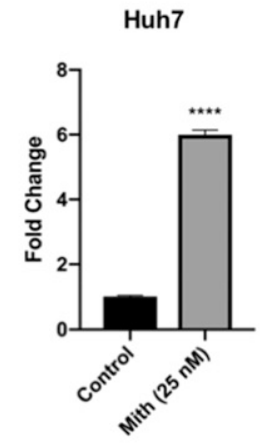

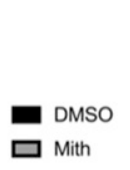

B

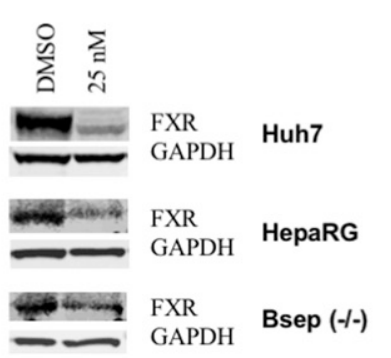

E

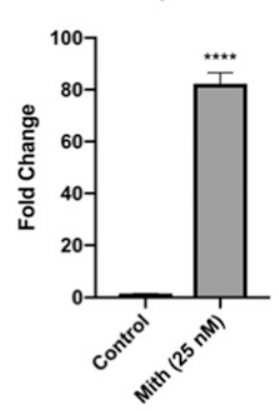

HepaRG
C
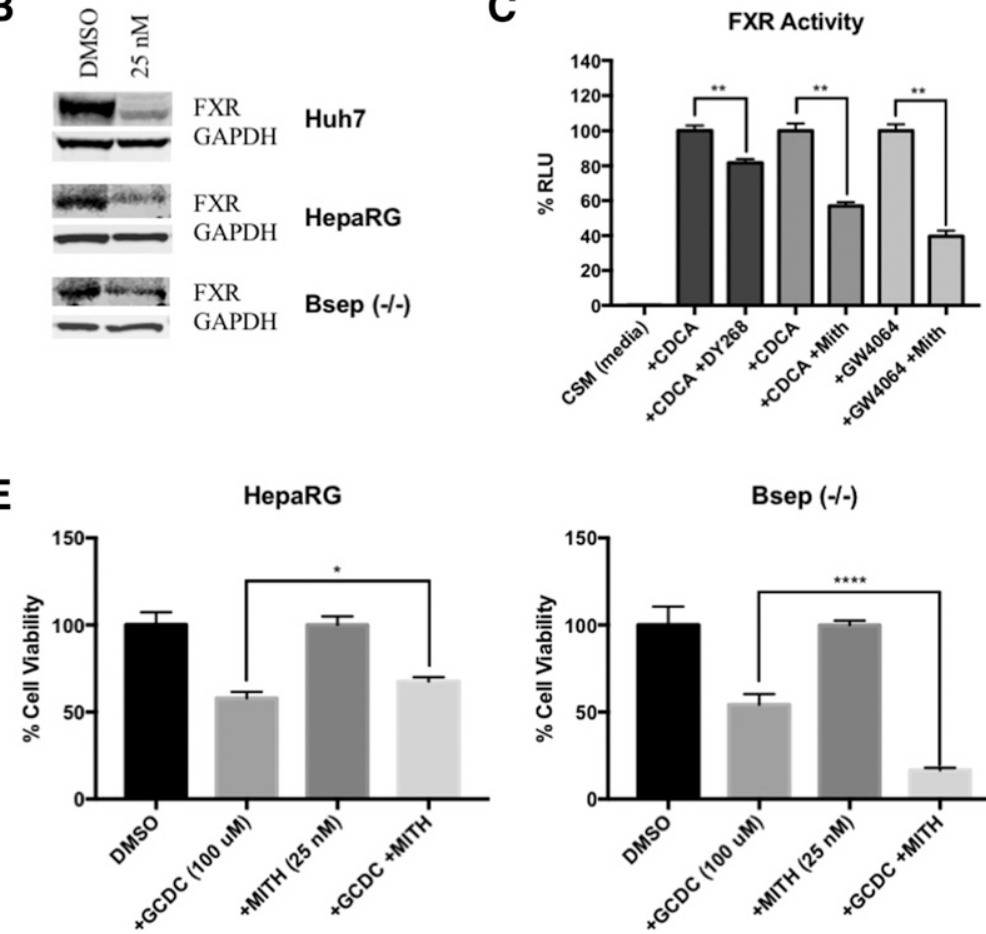

Bsep (-/-)

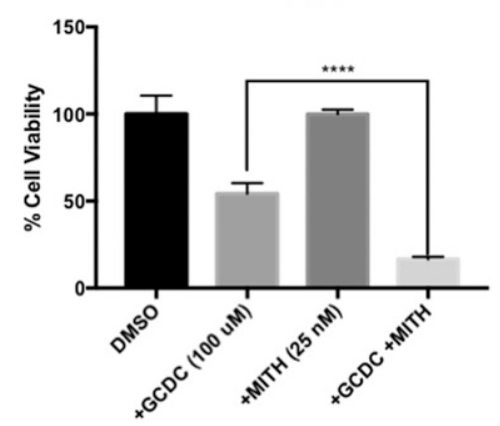

Fig. 3. (A) FXR mRNA was downregulated in all cell lines and primary human hepatocytes (PHH) tested. (B) FXR protein levels were similarly disrupted in all cell lines. (C) CDCA $(50 \mu \mathrm{M})$ and GW4064 $(300 \mathrm{nM})$ significantly increased FXR-GAL4 luciferase reporter activity in CHO cells, and such activity was reduced by a known inhibitor (DY268; $370 \mathrm{nM}$ ) and mithramycin $(300 \mathrm{nM})$. (D) Mithramycin increased expression of SHP in Huh7 and HepaRG cell lines. (E) Mithramycin did not affect GCDC-induced cellular toxicity in HepaRG cells, whereas mithramycin resulted in additional GCDC toxicity in HepaRG BSEP knockout cells. $* P<0.05 ; * * P<0.01$; and $* * * * P<0.0001$.

GCDC $(100 \mu \mathrm{M})$ toxicity in wild-type HepaRG cells, but did result in additional cytotoxicity in BSEP (-/-) cells (Fig. 3E). The data suggest mithramycin blocks both FXR expression and the ligand-dependent activity of FXR, resulting in bile acid-induced toxicity in cells that have a lower capacity to efflux bile.

Disruption of Bile Acid Transporter Expression and Disposition Facilitates Intrahepatic Bile Acid Accumulation. As standard monolayer cell cultures do not fully retain hepatic morphology and liver-specific metabolic functions (Marion et al., 2007), we evaluated mithramycin-induced alterations of transporter expression and bile acid disposition in SCHH. We first genotyped several lots of hepatocytes and identified one lot heterozygous at both $A B C B 4$ rs2302387 and $A B C B 11 \mathrm{rs} 4668115$ (C/T and G/A). A noncytotoxic concentration of mithramycin ( $20 \mathrm{nM}, 72$ hours) lowered the expression of SLC51A, SLC51B, SLC10A1, SLCO1B3, ABCC3, ABCC4, $A B C B 4, A B C B 11$, and $A B C B 1$, while increasing $S L C O 1 B 1$ expression (Fig. 4A) and altering the expression of many other uptake and efflux transporters (Supplemental Fig. 7). These data suggest that, contrary to observations in Huh7 and HepaRG cells grown in a monolayer, mithramycin reduces the expression of most bile transporters in polarized primary human hepatocytes grown in sandwich culture.

After 72-hour treatment with either DMSO, d4-CDCA, CsA, or mithramycin, accumulations of TCDCA, GCDCA, GCA, and TCA were measured in the cell culture media, within the cell, and within the bile canaliculus. When compared with vehicle control, mithramycin treatment displayed a trend toward TCA intracellular accumulation $(P=0.020)$ and bile duct accumulation $(P<0.106$; Fig. 4B). Similarly, mithramycin treatment showed a trend toward increased intracellular GCA accumulation $(P<0.068$; Fig. 4 C). Mithramycin significantly decreased the accumulation of TCDCA in cell culture media $(P=0.018)$, while increasing accumulation within the cell $(P \geq$ 0.09 ; Fig. 4D). The same effect was observed with the accumulation of highly toxic GCDCA in both the cell culture media $(P=0.041)$ and within the cell $(P=0.0048$; Fig. 4E). Whereas treatment with BSEP regulators d4-CDCA and CsA affected bile acid production, mithramycin did not alter total bile acid content in the sandwich culture system (Fig. 4F). Consistent with the hypothesis that mithramycin treatment results in bile acid accumulation within cells, mithramycin treatment significantly increased accumulation of all bile acids when compared with DMSO treatment by $35 \%(P<$ 0.0001), in direct contrast to d4-CDCA and CsA (Fig. 4G).

\section{Discussion}

In the present study, we sought to examine potential mechanisms driving mithramycin-induced severe hepatotoxicity and optimize mithramycin therapy to achieve clinically useful plasma concentrations in a subset of patients with favorable genotypes. In an ongoing clinical trial, significant LFT changes and severe transaminitis, indicative of hepatic injury, resulting from 3-day mithramycin therapy prevented the achievement of plasma concentrations above $20 \mathrm{nM}$ in patients with various thoracic malignancies. Using a pharmacogenomic drug metabolism multigene panel, we found mithramycin-induced AST and ALT elevations to be most strongly correlated with genetic 


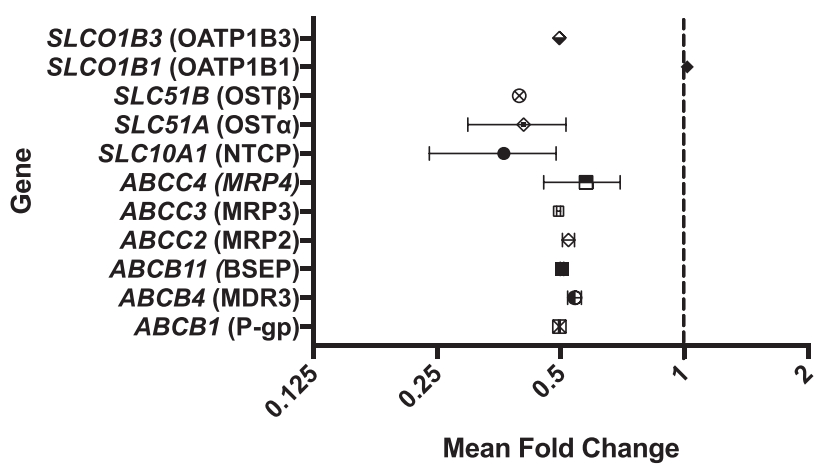

B

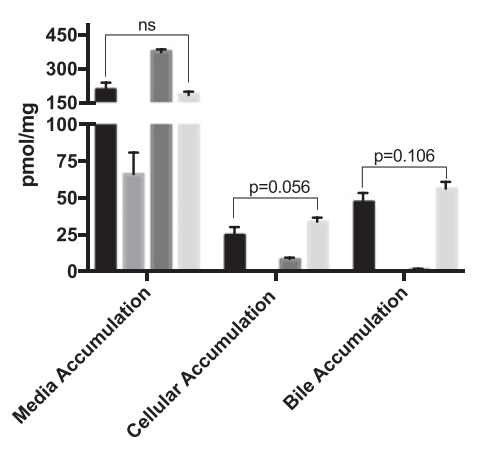

D

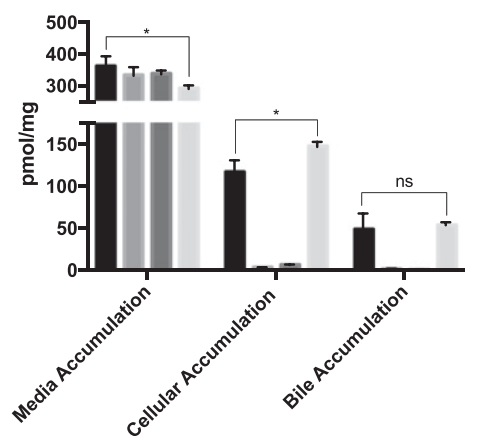

$\mathbf{F}$

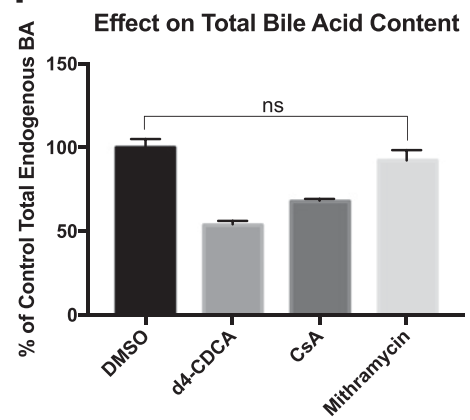

C

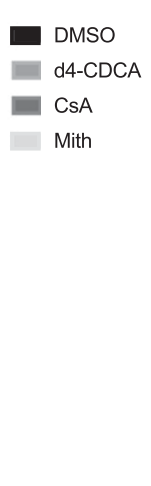

DMSO

d4-CDCA

CsA

Mith

E
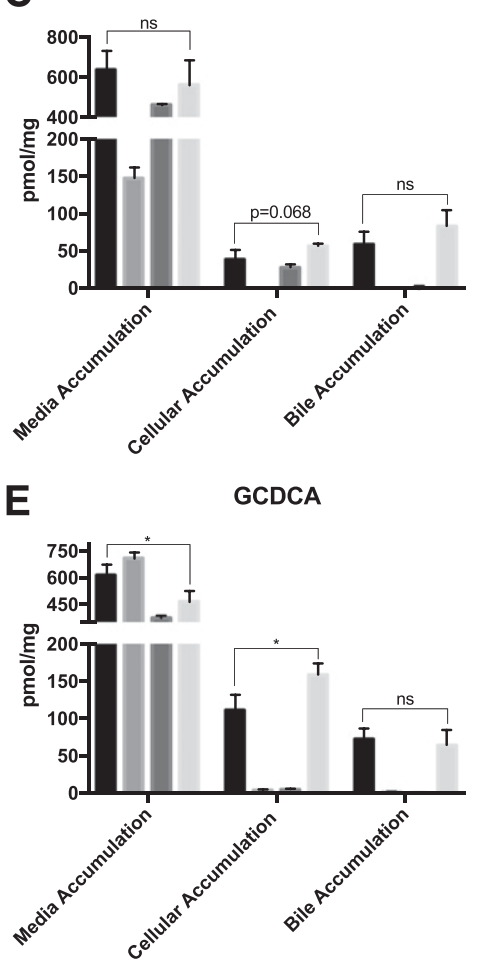

G

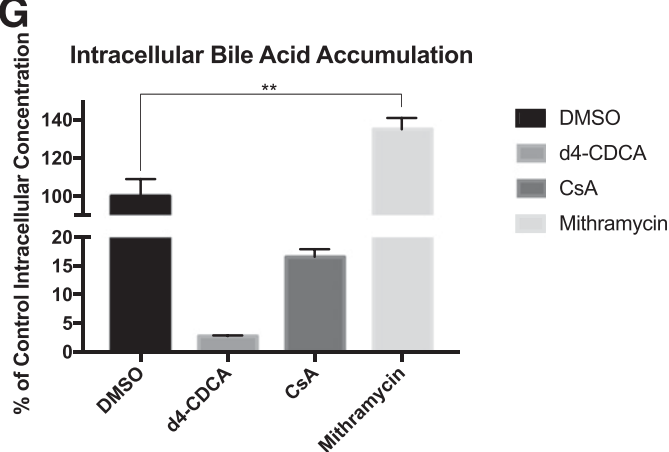

Fig. 4. (A) Mithramycin reduced the expression of 10/11 hepatic transporters in primary human hepatocytes. (B) TCA, (C) GCA, (D) TCDCA, and (E) GCDCA accumulation was tested in primary human hepatocytes pretreated with DMSO, d4-CDCA, CsA, and mithramycin for 72 hours. (F) The amount of total bile acid after treatment was calculated as a percentage found in DMSO-treated cells. (G) The intracellular accumulation of all bile acids was combined and plotted as a percentage of DMSO-treated control cell values. ns, non-significant. $* P<0.05$; and ${ }^{* *} P<0.01$.

variants in $\mathrm{ABCB} 11$ and $\mathrm{ABCB} 4$, which are both involved in the majority of canalicular bile flow in the liver (Chan and Vandeberg, 2012).
Previous studies have shown that allelic variants and mutations leading to severe deficiencies of ABCB11 and $\mathrm{ABCB} 4$ function are associated with phenotypically-related 
hereditary liver disorders: benign recurrent intrahepatic cholestasis types 2 and 3 and progressive familial intrahepatic cholestasis types 2 and 3 (Curreri and Ansfield, 1960; Sewell and Ellis, 1966; Chan and Vandeberg, 2012; Srivastava, 2014). Toxic accumulation of bile acids in the liver is a known cause of hepatocyte injury (Chiang and Ferrell, 2018), and each of these diseases results from impairment of bile homeostasis, resulting in cholestasis, derangement of liver function, and transaminitis. We found that mithramycin toxicity was also associated with other genes involved in bile disposition, including $A B C C 2$ and $C Y P 8 B 1$. These findings led to the hypothesis that mithramycin-induced hepatotoxicity occurs via cellular deregulation of bile homeostasis, particularly in patients expressing less hepatic ABCB11 and ABCB4.

The present data are the first to suggest that the $A B C B 4$ rs2302387 (L59L) and $A B C B 11$ rs4148115 polymorphisms are associated with expression of both transporters in patientderived human hepatocytes, and that these variants have clinical consequences. The synonymous $A B C B 4$ rs2302387 polymorphism (L59L) is in strong linkage disequilibrium with a polymorphism ( $\mathrm{rs} 4148805,-1584 \mathrm{C}>\mathrm{T}$ ) that is known to disrupt a critical " $\mathrm{C}$ " base in an enhancer element of $A B C B 4$ (CCAAT vs. TCAAT) and thereby reduces $A B C B 4$ expression in hepatocytes (Jang et al., 2013). The rs4148115 polymorphism is in a large disequilibrium block as well; however, it is not in strong linkage with polymorphisms that have previously been associated with BSEP function (Lang et al., 2007; Nieuweboer et al., 2015). Mapping studies are required to fully clarify which variant(s) drives differences in hepatic expression, but rs2302387 and rs4148115 are nevertheless associated with mithramycin-induced acute transaminitis in two independent studies taking place in adult patients with thoracic malignancies and in pediatric patients with Ewing sarcoma. Mithramycin toxicity is therefore predicted to be most severe in patients harboring variant genotypes conferring low expression of $A B C B 4$ and $A B C B 11$.

Consistent with its role as a transcription factor inhibitor, mithramycin blocks approximately $75 \%$ of transcription in animal liver (Yarbro et al., 1966). Our data further indicate that mithramycin alters the expression of most bile transporters in various hepatocyte cell lines. This effect was most pronounced in HepaRG cells lacking BSEP, in which most transporters were downregulated. In HepaRG wild-type cells, coadministration of bile acids with mithramycin significantly decreased the expression of the canalicular bile transporters, $A B C B 11$ and $A B C B 4$. HepaRG cells appear to respond to $\mathrm{ABCB} 11$ and $\mathrm{ABCB} 4$ inhibition by reducing the expression of bile uptake (SLCO10A1, NTCP), while increasing expression of the basolateral efflux transporters $(S L C 51 A / B$, OST $\alpha / \beta)$. In primary human hepatocytes, mithramycin reduced the expression of all bile transporters (except SLCO1B1), resulting in greater intracellular concentrations of bile species. Bile acids act as signaling molecules to activate certain hepatic nuclear receptors, including the major bile acid sensor FXR. Once activated, FXR alters the expression of numerous hepatic transporters to decrease bile acid uptake while upregulating bile acid efflux (Cui et al., 2012; Jackson et al., 2018). Consistent with these findings, we found that mithramycin inhibits both the transcription and expression of FXR, as well as its association with FXR ligand-activating bile acids (i.e., CDCA), leading to subsequent deregulation of bile acid homeostasis in hepatocytes. Such inhibition of FXR with concurrent deregulation of bile transport is in contrast with liver injury caused by direct ABCB 11 inhibitors. For instance, CsA blocks ABCB11 and activates FXR-mediated compensatory mechanisms as intracellular bile accumulates (Jackson et al., 2018), whereas mithramycin downregulates ABCB11 while simultaneously blocking FXR-mediated cellular responses.

Consistent with this view and unlike CDCA and CsA, mithramycin did not decrease bile synthesis. To our surprise, we also did not find mithramycin to be an inhibitor of BSEPregulated bile acid transport, as are a variety of other hepatotoxic therapeutics (Qiu et al., 2016). Mithramycin instead potentiated GCDC-induced toxicity in BSEP (-/-) cells. We did not find that mithramycin inhibited a variety of other nuclear receptors; albeit, we did not test whether mithramycin inhibited these in the presence of ligand.

Mithramycin appears to function as both an inhibitor of FXR gene expression and a strong antagonist of ligandinduced activation of FXR. Mithramycin therefore deregulates bile flow through several hepatic transporters and results in intracellular accumulation of bile acids. In HepaRG BSEP $(-/-)$ cells, such accumulation of bile results in cytotoxicity. Taken together, these data provide evidence that mithramycin induces cholestasis in individuals harboring genetic profiles susceptible to bile acid accumulation (i.e., $A B C B 4$ and/or $A B C B 11$ gene variants). A dose-escalation clinical trial is currently underway to test mithramycin therapy in patients identified as carrying only wild-type alleles at both rs2302387 and rs4668115 in germline DNA (NCT01624090). Following accrual of three additional patients to this trial, we found that CYP8B1 became even more strongly associated with mithramycin-induced hepatotoxicity and that a hepatic transporter, RALBP, was also associated with mithramycin outcome (data not shown). We are currently amending the clinical trial to account for these SNPs in addition to rs2302387 and rs4668115, and we are characterizing the mechanism by which CYP8B1 and RALBP SNPs affect mithramycininduced LFT elevations. Identifying patients who are at risk for mithramycin-induced hepatic injury could inform whether patients with optimal genetic profiles can tolerate this therapy at higher concentrations, potentially recapitulating drug exposure levels achieved in preclinical studies and improving clinical responses.

\section{Authorship Contributions}

Participated in research design: Sissung, Peer, Jackson, Brouwer, Grohar, Glod, Widemann, Heller, Schrump, Figg.

Conducted experiments: Sissung, Huang, Hauke, McCrea, Peer, Barbier, Strope, Ley, Zhang, Hong, Jackson, Grohar, Glod, Widemann, Heller, Schrump, Figg.

Contributed new reagents or analytic tools: Widemann, Schrump, Figg.

Performed data analysis: Sissung, Peer, Venzon, Jackson.

Wrote or contributed to the writing of the manuscript: Sissung, Huang, Venzon, Jackson, Brouwer, Schrump, Figg.

\section{References}

Arbitrio M, Di Martino MT, Scionti F, Agapito G, Guzzi PH, Cannataro M, Tassone P, and Tagliaferri P (2016) DMET ${ }^{\mathrm{TM}}$ (Drug Metabolism Enzymes and Transporters): a pharmacogenomic platform for precision medicine. Oncotarget 7:54028-54050.

Baum M (1968) A clinical trial of mithramycin in the treatment of advanced malignant disease. Br J Cancer 22:176-183.

Blume SW, Snyder RC, Ray R, Thomas S, Koller CA, and Miller DM (1991) Mithramycin inhibits SP1 binding and selectively inhibits transcriptional activity of the dihydrofolate reductase gene in vitro and in vivo. $J$ Clin Invest 88: $1613-1621$ 
Bohan A and Boyer JL (2002) Mechanisms of hepatic transport of drugs: implications for cholestatic drug reactions. Semin Liver Dis 22:123-136.

Chan $\mathrm{J}$ and Vandeberg JL (2012) Hepatobiliary transport in health and disease. Clin Lipidol 7:189-202.

Chiang JYL and Ferrell JM (2018) Bile acid metabolism in liver pathobiology. Gene Expr 18:71-87.

Cui JY, Aleksunes LM, Tanaka Y, Fu ZD, Guo Y, Guo GL, Lu H, Zhong XB, and Klaassen CD (2012) Bile acids via FXR initiate the expression of major transporters involved in the enterohepatic circulation of bile acids in newborn mice. Am J Physiol Gastrointest Liver Physiol 302:G979-G996.

Curreri AR and Ansfield FJ (1960) Mithramycin-human toxicology and preliminary therapeutic investigation. Cancer Chemother Rep 8:18-22.

Dawson PA, Lan T, and Rao A (2009) Bile acid transporters. J Lipid Res 50: 2340-2357.

Green L and Donehower RC (1984) Hepatic toxicity of low doses of mithramycin in hypercalcemia. Cancer Treat Rep 68:1379-1381.

Grohar PJ, Glod J, Peer CJ, Sissung TM, Arnaldez FI, Long L, Figg WD, Whitcomb P, Helman LJ, and Widemann BC (2017) A phase I/II trial and pharmacokinetic study of mithramycin in children and adults with refractory Ewing sarcoma and EWS-FLI1 fusion transcript. Cancer Chemother Pharmacol 80:645-652.

Grohar PJ, Woldemichael GM, Griffin LB, Mendoza A, Chen QR, Yeung C, Currier DG, Davis S, Khanna C, Khan J, et al. (2011) Identification of an inhibitor of the EWS-FLI1 oncogenic transcription factor by high-throughput screening. $J$ Nat Cancer Inst 103:962-978.

Halilbasic E, Claudel T, and Trauner M (2013) Bile acid transporters and regulatory nuclear receptors in the liver and beyond. J Hepatol 58:155-168.

Huang L, Zhao A, Lew JL, Zhang T, Hrywna Y, Thompson JR, de Pedro N, Royo I Blevins RA, Peláez F, et al. (2003) Farnesoid X receptor activates transcription of the phospholipid pump MDR3. J Biol Chem 278:51085-51090.

Jackson JP, Freeman K, Friley WW, St. Claire RL III, Black CB, and Brouwer KL (2016) Basolateral efflux transporters: a potentially important pathway for the prevention of cholestatic hepatotoxicity. Appl In Vitro Toxicol 2 1019-1026.

Jackson JP, Freeman KM, St. Claire RL III, Black CB, and Brouwer KL (2018) Cholestatic drug induced liver injury: a function of bile salt export pump inhibition and farnesoid X receptor antagonism. Appl In Vitro Toxicol 4:265-279.

Jang GH, Kim TH, Choe Y, Ham A, and Choi JH (2013) Functional characterization of genetic variations in the MDR3 promoter. Biochem Biophys Res Commun 430 $1312-1318$.

Kennedy BJ (1970) Mithramycin therapy in advanced testicular neoplasms. Cancer 26:755-766.

Kofman S and Eisenstein R (1963) Mithramycin in the treatment of disseminated cancer. Cancer Chemother Rep 32:77-96.

Lang C, Meier Y, Stieger B, Beuers U, Lang T, Kerb R, Kullak-Ublick GA, Meier PJ, and Pauli-Magnus C (2007) Mutations and polymorphisms in the bile salt export pump and the multidrug resistance protein 3 associated with drug-induced liver injury. Pharmacogenet Genomics 17:47-60.

Li J, Gao H, Meng L, and Yin L (2017) Mithramycin inhibits epithelial-tomesenchymal transition and invasion by downregulating SP1 and SNAI1 in salivary adenoid cystic carcinoma. Tumour Biol 39:1010428317708697.

$\mathrm{Li} \mathrm{L}$ and Davie JR (2010) The role of Sp1 and Sp3 in normal and cancer cell biology. Ann Anat 192:275-283.

Liu XJ, Li L, Liu XJ, Li Y, Zhao CY, Wang RQ, and Zhen YS (2017) Mithramycinloaded mPEG-PLGA nanoparticles exert potent antitumor efficacy against pancreatic carcinoma. Int $J$ Nanomedicine 12:5255-5269.

Lombó F, Menéndez N, Salas JA, and Méndez C (2006) The aureolic acid family of antitumor compounds: structure, mode of action, biosynthesis, and novel derivatives. Appl Microbiol Biotechnol 73:1-14.
Makishima M, Okamoto AY, Repa JJ, Tu H, Learned RM, Luk A, Hull MV, Lustig KD, Mangelsdorf DJ, and Shan B (1999) Identification of a nuclear receptor for bile acids. Science 284:1362-1365.

Marion TL, Leslie EM, and Brouwer KL (2007) Use of sandwich-cultured hepatocytes to evaluate impaired bile acid transport as a mechanism of drug-induced hepatotoxicity. Mol Pharm 4:911-918.

Merk D, Steinhilber D, and Schubert-Zsilavecz M (2014) Characterizing ligands for farnesoid X receptor--available in vitro test systems for farnesoid X receptor modulator development. Expert Opin Drug Discov 9:27-37.

Nieuweboer AJ, Smid M, de Graan AJ, Elbouazzaoui S, de Bruijn P, Martens JW, Mathijssen RH, and van Schaik RH (2015) Predicting paclitaxel-induced neutropenia using the DMET platform. Pharmacogenomics 16:1231-1241.

Plass JR, Mol O, Heegsma J, Geuken M, Faber KN, Jansen PL, and Müller M (2002) Farnesoid $\mathrm{X}$ receptor and bile salts are involved in transcriptional regulation of the gene encoding the human bile salt export pump. Hepatology 35:589-596.

Qiu X, Zhang Y, Liu T, Shen H, Xiao Y, Bourner MJ, Pratt JR, Thompson DC, Marathe P, Humphreys WG, et al. (2016) Disruption of BSEP function in HepaRG cells alters bile acid disposition and is a susceptive factor to drug-induced cholestatic injury. Mol Pharm 13:1206-1216.

Rao M, Atay SM, Shukla V, Hong Y, Upham T, Ripley RT, Hong JA, Zhang M, Reardon E, Fetsch P, et al. (2016) Mithramycin depletes specificity protein 1 and activates p53 to mediate senescence and apoptosis of malignant pleural mesothelioma cells. Clin Cancer Res 22:1197-1210.

Ream NW, Perlia CP, Wolter J, and Taylor SG III (1968) Mithramycin therapy in disseminated germinal testicular cancer. JAMA 204:1030-1036.

Reuben A, Koch DG, and Lee WM; Acute Liver Failure Study Group (2010) Druginduced acute liver failure: results of a U.S. multicenter, prospective study. Hepatology 52:2065-2076.

Roth J, Peer CJ, Widemann B, Cole DE, Ershler R, Helman L, Schrump D, and Figg WD (2014) Quantitative determination of mithramycin in human plasma by a novel, sensitive ultra-HPLC-MS/MS method for clinical pharmacokinetic application. J Chromatogr B Analyt Technol Biomed Life Sci 970:95-101.

Safe S, Imanirad P, Sreevalsan S, Nair V, and Jutooru I (2014) Transcription factor Sp1, also known as specificity protein 1 as a therapeutic target. Expert Opin Ther Targets 18:759-769.

Sankpal UT, Maliakal P, Bose D, Kayaleh O, Buchholz D, and Basha R (2012) Expression of specificity protein transcription factors in pancreatic cancer and their association in prognosis and therapy. Curr Med Chem 19:3779-3786.

Sewell IA and Ellis H (1966) A trial of mithramycin in the treatment of advanced malignant disease. Br J Cancer 20:256-263.

Singh DK, Kollipara RK, Vemireddy V, Yang XL, Sun Y, Regmi N, Klingler S, Hatanpaa KJ, Raisanen J, Cho SK, et al. (2017) Oncogenes activate an autonomous transcriptional regulatory circuit that drives glioblastoma. Cell Rep 18.961-976.

Srivastava A (2014) Progressive familial intrahepatic cholestasis. J Clin Exp Hepatol 4:25-36

Yarbro JW, Kennedy BJ, and Barnum CP (1966) Mithramycin inhibition of ribonucleic acid synthesis. Cancer Res 26:36-39.

Zhang M, Mathur A, Zhang Y, Xi S, Atay S, Hong JA, Datrice N, Upham T, Kemp CD, Ripley RT, et al. (2012) Mithramycin represses basal and cigarette smoke-induced expression of ABCG2 and inhibits stem cell signaling in lung and esophageal cancer cells. Cancer Res 72:4178-4192.

Zhang Y, Jackson JP, St Claire RL III, Freeman K, Brouwer KR, and Edwards JE (2017) Obeticholic acid, a selective farnesoid X receptor agonist, regulates bile acid homeostasis in sandwich-cultured human hepatocytes. Pharmacol Res Perspect 5(4):e003296.

Address correspondence to: Dr. William D. Figg, 9000 Rockville Pike, Building 10, Room 5A01, Bethesda, MD 20892. E-mail: figgw@mail.nih.gov 